\title{
BONDAD DE LA RACIONALIDAD* \\ Un homenaje a la memoria de Norberto Bobbio
}

\author{
Agustín Squella \\ Universidad de Valparaíso, Chile
}

RESUMEN. En este trabajo el autor rinde un personal homenaje a Norberto BoBBIO al analizar algunos aspectos de su pensamiento en los que se muestra la idea de que existe una bondad de la racionalidad, es decir, que una posibilidad de ser buenos consiste en comportarse racionalmente. Uno de ellos se aprecia en los planteamientos del maestro turinés en favor de un liberalismo social encaminado al reconocimiento y protección de las libertades básicas de los individuos, así como a la eliminación de las desigualdades más manifiestas. Un segundo aspecto se advierte en la defensa de un pacifismo institucional en el que se obtenga la paz a través del Derecho. Finalmente, un tercer aspecto en el que se apreciaría una bondad de la racionalidad se refiere a la manera en que BовBı entendió los fenómenos de la religión y la religiosidad.

Palabras clave: Norberto Bobbio, liberalismo social, pacifismo institucional.

ABSTRACT. In this paper the author pays personal homage to Norberto BoBBIO, analysing certain aspects of his thought in which he presents the idea that goodness in rationality exists, that is to say, that a possibility of being good consists in behaving rationally. One of these aspects can be seen in the master from Turin's proposals in favour of a social liberalism leading to the recognition and protection of individuals's fundamental liberties, as well as the elimination of the most evident inequalities. A second aspect can be appreciated in the defence of institutional pacifism, in which peace can be obtained through law. Finally, a third aspect, in which goodness in rationality can be seen, makes reference to the way in which BовBı understood the phenomena of religion and religiousness.

Keywords: Norberto Bobbio, social liberalism, institutional pacifism.

* Ponencia leída en la mesa en memoria de Norberto BobBIO, con motivo del XXII Congreso Mundial de Filosofía del Derecho y Filosofía Social, Granada, 29 de mayo de 2005, en la que intervinieron también Elías Díaz, Michelangelo Bovero, Richard Bellamy, Alfonso Ruiz Miguel, Celso Lafer y Luigi FERRAJOLI. 


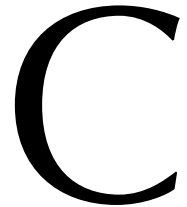

omo todos quienes participan en esta mesa, y como muchos de los que están en la platea, tengo una historia personal con BOBBIO. Una historia que se remonta a poco más de 20 años, concretamente a 1983, año en que empecé a preparar un número especial de la Revista de Ciencias Sociales de la Universidad de Valparaíso en homenaje al maestro de Torino, la misma revista que ha dedicado volúmenes monográficos a SAVIGNY, IHERING, KeLSEN, Ross, Hart, DwOrkin y, últimamente, a John RAwls. Pero antes de referir brevemente esa historia, quisiera señalar que el título de esta ponencia quiere significar que hay bondad en la racionalidad, o sea, que una posibilidad de ser buenos consiste en comportarse racionalmente. Si se quisiera ponerlo de este otro modo, existe una bondad que resulta no de mover el corazón, sino de mover la cabeza, una bondad que puede ser incluso superior a la que a veces sale del puro corazón y, ni que decir, muy superior a la que se reduce a esas meras declaraciones orales o escritas con las que pretenden buenos, o aparecer como tales, quienes hablan y escriben de bondad, pero que en su vida práctica se comportan muy lejos de ésta. Lo que sucede por momentos, al menos en el país de donde vengo, es que en materias de índole moral se prefiera hablar antes de valores que de virtudes, como si en al campo moral importaran más los valores que se declaran que las virtudes que se practican.

A BOBBIO vine a conocerle personalmente un año más tarde, en 1984, con ocasión de un congreso internacional de filosofía del derecho que Enrico PATTARO organizó en Bologna. BовBIo me miró con cierta incredulidad cuando me acerqué a él y le dije que estaba preparando una obra colectiva en su homenaje. Mayor incredulidad mostró dos años más tarde, aunque siempre con benevolencia, cuando visitó la Universidad de Valparaíso y comprobó que el anunciado volumen aún no veía la luz. Éste vino a aparecer recién en 1987, y todavía recuerdo la alegría con que puse en el correo, con mis propias manos, el ejemplar destinado a BOBBIO.

De allí en adelante intercambiamos no más de dos cartas cada año, a raíz de la publicación de algún nuevo libro o artículo suyo. Sus cartas eran siempre muy breves y estaban escritas con una caligrafía pequeña y progresivamente temblorosa.

En 1992 tuvo lugar en Santander un curso de verano sobre BoBBIO, organizado por la Universidad Internacional Menéndez Pelayo, en el que intervinimos varios estudiosos de su obra, capitaneados por el hoy rector de la Universidad Carlos III, Gregorio PECESBARBA. El curso debía ser clausurado por el propio BOBBIO, quien en esos mismos días tuvo que ser sometido en Torino a una intervención quirúrgica de urgencia. Todos pensamos, cómo no, en el próximo fin del maestro, pero he aquí que BOBBIO se recuperó y produjo en los años posteriores a lo menos tres nuevos libros. Recuerdo hasta hoy la emoción con que PECES-BARBA leyó el texto que BOBBIO iba a presentar en la ocasión, y que pudimos recibir gracias al fax.

Allí, en el palacio de La Magdalena, a orillas del Cantábrico, en medio de una atmósfera cargada de admiración, respeto y preocupación por el maestro lejano y enfermo, BOBBIO nos dijo que «la vejez es el crepúsculo que anuncia la noche» y que «la melancolía es la conciencia de lo insatisfecho, de lo incompleto», pero señaló también que «hay bondad en la racionalidad» y que «en el mundo de los viejos cuentan más los afectos que los conceptos». 
Como ustedes ven, es de una de aquellas frases de BoBBio de donde salió el título de mi intervención en esta mesa en su memoria, de aquella frase en la que él certifica que «hay bondad en la racionalidad», una idea que me propongo desarrollar brevemente a continuación, no sin antes completar el relato de mi historia con BOBBIO.

En 2002, una de mis hijas pasó por Torino y llevó consigo un ejemplar de mi libro Filosofía del Derecho, recién aparecido, con el encargo preciso de entregarlo a BOBBIO en su casa de Via Sacchi, 66. Fue atendida por la empleada, quien le dijo que BoBBIO descansaba en ese instante y que no estaba en condiciones de recibirla. Nunca recibí el acuse de recibo, aunque me queda la esperanza de que el libro haya estado siquiera un momento en sus manos. Ese libro, entre otros cuatro capítulos, incluye uno sobre «Democracia y Derecho» y otro sobre «Positivismo jurídico», y ambos deben muchísimo a las ideas y planteamientos de BOBвIO en ambas materias. Con posterioridad, en 2004, luego de la muerte de BOBBIO, organizamos en Valparaíso un encuentro sobre su obra. Hubo más de 20 ponencias que formarán parte de un libro que hoy está en prensa. Por otra parte, hace un par de meses, la editorial Fondo de Cultura Económica publicó en Chile un librito mío de divulgación de las ideas de BoBBIO, titulado Norberto Bobbio: un hombre fiero y justo.

Debo mucho a las ideas de BobBio, sobre todo a las ideas políticas del maestro y, muy especialmente, a su siempre renovado discurso a favor de un liberalismo social, por entender que no se puede tener una sociedad decente si a los individuos que la forman no se les reconocen y protegen sus libertades básicas, y por entender, asimismo, que una sociedad decente no es sólo una sociedad de libertades, sino una donde hayan desaparecido las desigualdades más manifiestas e injustas entre los hombres. Si quisiera decirlo con una sola frase, una sociedad decente, además de ser una sociedad de libertades, es aquella donde las personas pueden comer a lo menos tres veces al día, es decir, una sociedad donde existe cierta igualdad en las condiciones materiales de vida de la gente. Y donde comer, por lo mismo, significa no sólo alimentarse, sino tener satisfechas las necesidades básicas de salud, educación, vivienda y vestuario.

No es la realidad que hoy tiene Europa, pero sí muchos de los países de América Latina y, desde luego, de África, y esa realidad — sin necesidad de ponernos demasiado dramáticos- se parece por momentos a la de un trasatlántico donde unos pocos viajan cómodamente instalados en camarotes de lujo, mientras la mayoría se las arregla como puede y tiende sus mantas sobre la cubierta y en bodegas, sin olvidar a los que nadan alrededor de la nave y tratan desesperadamente de subir a ella.

Para llegar a tener una sociedad de libertades y una cierta igualdad en las condiciones de vida de las personas no existen los atajos, sino el camino largo y gradual que hace posible la democracia, según todos hemos aprendido durante las últimas décadas. Pero este aprendizaje no puede significar que demos por definitivamente buena la alianza entre capitalismo y democracia, y nos sentemos a esperar a que los frutos maduren y alcancen para todos. Fukuyama nunca tuvo razón al decretar el fin de la historia, entendido como el agotamiento de las posibilidades humanas de idear e instaurar un sistema mejor que el que resulta de la alianza entre capitalismo y democracia. Tal es únicamente un modelo, quizás el modelo, pero no al modo de un patrón único, ya terminado de una vez para siempre, inflexible, que admita un solo y mismo 
tipo de aplicación, de manera que la imaginación política, económica y moral de la humanidad — como señala el escritor Carlos Fuentes - aún tiene campo fértil donde moverse y - sobre todo en el caso de América Latina - de igualar algún día a nuestra imaginación verbal.

Pues bien: lo dicho es un ejemplo, en el caso de BoBbio, tanto de bondad como de racionalidad, o, mejor aún, de bondad de la racionalidad, de un bien que es posible alcanzar a partir del aprendizaje y el discernimiento. Como se ha dicho tantas veces, el liberalsocialismo de BoBBIO es una fórmula química inestable. Todavía más, el propio BOBBIO reconocía que, hasta ahora, nadie ha encontrado la manera de poner de acuerdo los derechos de la libertad con las exigencias de la justicia social, aunque ello no quita que el liberalsocialismo sea una fórmula que indica a la vez una dirección. Una dirección que supone no la exclusión ni menos el sacrificio de la libertad en nombre de la igualdad ni el de ésta en nombre de aquélla, sino uno de esos ajustes o compensaciones entre valores distintos, de los que hablaba Isaiah BERLIN, y que sólo son posibles si uno se pregunta cuánto de esto por cuánto de aquello, es decir, cuánta justicia por cuánta compasión, cuánto orden por cuánta libertad, y cuánta libertad por cuánta igualdad.

Es cosa sabida, asimismo, que BOBBIO busca la paz —otro bien- no por medio del desarme ni menos de las grandes y pomposas declaraciones tan frecuentes a favor de la misma, sino mediante el Derecho, es decir, mediante esa técnica social que los hombres producen para cumplir diversas funciones y conseguir ciertos fines, entre éstos, precisamente, el de instalar una paz relativa en las relaciones interpersonales y, desde luego, en las de carácter interestatal.

BOBBIO propicia un pacifismo institucional que haga algún día posible, a nivel del planeta, lo que desde hace un tiempo ha ocurrido ya al interior del Derecho interno de cada Estado, a saber, que el Derecho consiga el monopolio del uso de la fuerza, de manera que el empleo de ésta por un Estado en contra de otro Estado sea no sólo un comportamiento prohibido, esto es, un ilícito, y que, además, no predomine entre los Estados la ley del más fuerte.

Por lo demás, si nadie niega que la mínima función que cabe esperar del Derecho es la prevención de conflictos, así como la resolución de éstos por medios pacíficos y en sedes y por intermedio de procedimientos que el propio Derecho preestablece, ¿quién podría dudar del papel que cabe al Derecho en la prevención de ese tipo especial y gravísimo del conflicto que llamamos guerra?

BOBвIO sabe bien que para la observancia de principios morales «se necesita mucho más que su justificación racional». «La experiencia histórica —advierte- demuestra que se requiere la amenaza de penas terrenales», puesto que la creencia en penas ultraterrenales «se va reduciendo cada vez más». Entonces, es aquí el momento en que entra en escena el Derecho, pues éste desalienta las conductas que prohíbe por medio de la amenaza de sanciones coactivas. En tal sentido, como decía mi viejo maestro de filosofía del derecho en Valparaíso, «el derecho es la consagración del escepticismo», puesto que amén de exigir comportamientos que todos consideramos deseables (que los pactos se cumplan, por ejemplo) y de prohibir otros estimados indeseables (como quitar la vida a otro), cuenta con que en más de un caso alguien dejará sin observar sus deberes jurídicos y, por lo mismo, junto con establecer éstos, predetermina el espe- 
cífico castigo, pena o consecuencia desfavorable que deberá hacerse efectiva sobre el infractor.

Si a nivel de cada Estado se pasó ya del estado de naturaleza a la sociedad civil, lo propio tendría que ocurrir en el ámbito internacional. En palabras del propio BoBBIO, «el pacifismo jurídico es aquel que concibe el proceso de formación de una sociedad internacional en la que los conflictos entre estados se resuelven sin recurrir a la guerra, en última instancia en analogía con el proceso que, según la hipótesis contractualista, habría dado lugar al Estado».

Pero cómo, cómo hacer — se pregunta BOBBIO— para avanzar más rápidamente en esa dirección, tal como tendríamos que hacerlo también — volviendo al primer punto de mi exposición- para conseguir sociedades más decentes, o sea, más libres y a la par más igualitarias. Cómo hacer para avanzar a paso más firme en ese proceso de «acumulación civilizatoria» - como lo ha denominado Ernesto OTTONE- y del cual «surgen los derechos, las libertades y las igualdades».

Tenemos cada cual que «aportar nuestra piedra, por pequeña que sea, a la construcción del gran edificio». Todos, incluso los escépticos, lo que podamos creer que las cosas no mejorarán o que irán definitivamente mal, puesto que, como repite BOBBIO una y otra vez, todos tenemos derecho a ser escépticos en cuanto a la razón y a creer que las cosas irán mal, aunque a lo que no tenemos derecho es a ser escépticos en cuanto a la voluntad y a no hacer nada y sentarnos a esperar a que ocurra la tragedia. Aun siendo escépticos en cuanto a la razón, tenemos que ser optimistas en cuanto a la voluntad, lo cual quiere decir que si creemos que las cosas irán mal, tenemos el deber de hacer lo que esté a nuestro alcance para que vayan lo mejor posible.

Sí, «llevamos ya mucho retraso — escribe BOBBIO— respecto a las grandes aspiraciones de los hombres de buena voluntad», una constatación que el maestro hace no para deprimirnos e instarnos a abandonar la tarea, sino — como dice él一 para «no aumentarlo (el retraso) con nuestra desconfianza, nuestra indolencia o nuestro escepticismo». Entonces —remata-, «no hay tiempo que perder».

Otro de los aspectos en que BOBBio mostró que hay bondad en la racionalidad -y se trata del último que voy a desarrollar aquí- se refiere al modo como él entendió y vivió los fenómenos de la religión y la religiosidad. Calculen ustedes cómo entro ahora en un ámbito más íntimo del autor y, por tanto, también más impreciso, incierto y en alguna medida inescrutable, metiéndome así, de lleno, en las patas de los caballos, con el consiguiente riesgo de salir magullado, que es lo que con mayor probabilidad ocurrirá siempre a quien se inmiscuya en las extremidades ágiles, sensibles, delicadas, pero también fuertes, de esos nobles animales. ¿Han visto ustedes caer a un jinete en medio de una carrera de finasangres, sobre todo cuando marcha en el grupo de avanzada y es golpeado por los animales que vienen detrás? Se trata de algo fuerte, incluso para un hípico, como es mi caso, que ha presenciado muchas veces esa escena.

En efecto, decir que la concepción procedimental de la democracia que tiene BoвBio, que establece cómo se adoptan las decisiones de gobierno y no cuál es el contenido específico que ellas tendrán, y recordar, asimismo, que dicha forma de gobierno, junto con presuponer y garantizar ciertos derechos fundamentales de las personas, crea el escenario adecuado para que los diferentes puntos de vista acerca 
de cómo organizar la sociedad se encuentren, dialoguen, hagan concesiones recíprocas y alcancen acuerdos y transacciones propias de una forma de gobierno que acepta la gradualidad y en la que nadie gana ni pierde todo; decir todo eso - repito- es también pertinente a la hora de explicar cómo patentiza BoBBIO su postulado sobre la bondad de la racionalidad. Como dice el propio BoBBIO, la democracia no corta cabezas, las cuenta, y si no cortar cabezas es algo bueno, contarlas es racional. Eliminar el tiro de gracia del vencedor sobre el vencido es bueno, y sustituir ese tiro por el voto es racional. sidad?

Pero, ¿qué decir, en cambio, a propósito de BoBBIO, acerca de religión y religio-

Lo primero que tengo que decir al respecto es que a mí me impresionó mucho el texto con las últimas voluntades de BOBBIO, escrito por él cuando cumplió 90 años, y dado a conocer luego de su muerte. En ese escrito, BoBBio pidió un funeral civil, no religioso, porque, según dijo, «me he alejado ya demasiado tiempo de la Iglesia para regresar a hurtadillas a última hora». Sin embargo, agregó que creía «no haberme alejado nunca de la religión de mis padres, aunque sí de la Iglesia», añadiendo luego una declaración como ésta: «No me considero ni ateo ni agnóstico. Como hombre de razón y no de fe, se que estoy inmerso en el misterio que la razón no logra penetrar hasta el fondo, y que las distintas religiones interpretan de diversos modos».

«Hombre de razón y no hombre de fe» es un reconocimiento que BoBBio había hecho en varios de sus escritos anteriores. Una declaración que en uno de sus último diálogos, con Mauricio VIROLI, reiteró con fuerza al decir «mi concepción de la vida es profana, no sagrada», todo lo cual no se compatibiliza bien con la doble negación hecha en el escrito de sus últimas voluntades — «No me considero ni ateo ni agnóstico»-, puesto que un hombre que carece de fe y que está consciente de los límites de la razón para desentrañar el misterio de la existencia es lo que se considera habitualmente un agnóstico.

Entonces, ¿cómo entender que BoBвiO se resista a calificarse a sí mismo como agnóstico? Además, ¿cómo un hombre que dice carecer de fe puede decir que nunca se alejó de la religión de sus padres? ¿Y cómo se concilia una visión profana de la vida contenida en ese mismo diálogo con VIROLI, en las que BOBBIO afirma «soy religioso en cuanto tengo el sentido del misterio que nos rodea, pero no voy más allá?».

No tengo respuestas muy seguras para tales preguntas, salvo la demasiado fácil que consistiría en advertir que, también en este campo, BoBBIO cambia una y otra vez de opinión, porque nunca fue un autor que pensara en línea recta. Con todo, me gustaría señalar que los fenómenos del ateísmo y el agnosticismo están relacionados con la democracia, los derechos humanos, el liberalismo y el socialismo, puesto que, sin llegar a constituir religiones, se trata de cuatro causas de la modernidad que, de algún modo, han reducido las áreas de influencia de la religión y se han enfrentado incluso a ésta.

Por otra parte, BовВіо, como anticipamos en su momento, distingue "religiosidad" de "religión", donde "religiosidad" significa "tener el sentido de los propios límites", o, si se prefiere, compartir un profundo «sentido del misterio», aunque yo también me pregunto por qué utilizar la palabra "misterio" para aludir a lo que simplemente 
ignoramos. "Misterio", quiérase o no, es un término que tiene una connotación religiosa, en tanto que "ignorancia" es una palabra netamente profana. "Misterio" es una realidad arcana que no podemos develar, mientras que "ignorancia" alude meramente a no saber algo, sin admitir necesariamente la posibilidad de que ese "algo" exista.

En fin, concluyo con estas palabras de BOBBIO: «Cuando siento haber llegado al final de la vida sin haber encontrado una respuesta a las preguntas últimas, mi inteligencia es humillada y yo acepto esta humillación. La acepto y no trato de huir de esta humillación con la fe». Pues bien, y si no hubiera respuestas para eso que BOBBiO llama «preguntas últimas», ¿por qué sentir "humillación" por no haber encontrado respuestas a tales preguntas?

Lo que me pregunto, por último, es si BOBBIO echaba o no de menos a Dios, frase que tomo de Enrique TIERNO GALVÁN, quien decía que ser agnóstico «es no echar de menos a Dios», es decir, hallarse satisfactoriamente instalado en la propia finitud. BobBio, es claro, no supo de Dios, pero como «no creyente que continúa a pesar de todo permaneciendo en el umbral», ¿tuvo acaso añoranza de Dios?

Gianni VAtTimo, un creyente débil, amigo y compañero de BobBio en la Universidad de Torino, dice «Creo que creo», mientras que BoBBIO, un no creyente débil, afirma «Yo creo que no creo». Un creyente en sentido fuerte diría, simplemente, «Creo», en tanto que un no creyente en igual sentido diría «No creo». Es la común expresión «Creo que...» — que «creo» en el caso de VATTIMO, que «no creo» en el de BOBBIO- lo que los hace ser, respectivamente, un creyente y un no creyente en sentido débil.

Pues bien: creyentes y no creyentes débiles son buenas personas para la causa de la paz, cuando menos porque un no creyente débil se rehusará a aceptar fácilmente la idea de que sin Dios todo está permitido, mientras que un creyente débil no aceptará tampoco la idea contraria, es decir, que si hay Dios, y Él está de su lado, todo está permitido, en especial —en este último caso- el rechazo, la discriminación, la persecución o el directo aniquilamiento de los infieles, o sea, de los que no creen lo mismo en que creen los que creen.

Ya ven ustedes cómo esto, incluso al nivel de las solas palabras, se parece bastante a un laberinto, que no es sino una analogía más elegante que aquella otra de las patas de los caballos, que empleé antes. Pero si he querido mostrar este lado de BOBBIO —el de su religiosidad sin religión - es porque creo que algo, o quizás mucho, nos dice acerca de su persona y de su invariable mayor proximidad a la duda que a las certezas.

\section{$\triangle \quad$ DOXA 29 (2006)}

